\title{
Epidemiological and pathophysiological evidence supporting links between obstructive sleep apnoea and Type 2 diabetes mellitus
}

Chuen Peng $\underline{\text { Lee }}^{1}$, MBBS, MRCP, Clete A $\underline{\text { Kushida }}^{2}, \mathrm{MD}, \mathrm{PhD}$, John Arputhan $\underline{\text { Abisheganaden }}{ }^{1}$, MBBS, MRCP

\begin{abstract}
Obstructive sleep apnoea (OSA) and Type 2 diabetes mellitus (T2DM) are common diseases. The global prevalence of OSA is between $2 \%$ and $7 \%$ in general population cohorts. The worldwide prevalence of T2DM among adults (aged 20-79 years) was estimated to be 6.4\%. The concurrent presence of OSA and T2DM can be expected in the same patient, given their high prevalence and similar predisposition. We reviewed the overlapping pathophysiology of OSA and T2DM in this article.
\end{abstract}

Keywords: diabetes mellitus, obstructive sleep apnoea, pathophysiology, sleep-disordered breathing

\section{INTRODUCTION}

Obstructive sleep apnoea (OSA) and Type 2 diabetes mellitus (T2DM) are common diseases with a global prevalence of between $2 \%$ and $7 \%$ for OSA in general population cohorts, ${ }^{(1)}$ and an estimated worldwide prevalence of $6.4 \%$ for T2DM among adults (aged 20-79 years). ${ }^{(2)}$ Given the high prevalence, similar predisposition and overlapping pathophysiology of OSA and T2DM, they can be expected to occur concurrently in the same patient.

\section{PREVALENCE OF OSA AND T2DM}

Numerous studies have reported a high prevalence of OSA in subjects with T2DM. The Sleep AHEAD study found that $86 \%$ of its obese patients with T2DM had OSA; $30.5 \%$ of the participants had moderate OSA and $22.6 \%$ had severe OSA. ${ }^{(3)}$ However, this relationship was likely confounded by obesity. Screening for OSA using a single-channel nasal cannula, Einhorn et al found a high prevalence (48\%) of sleep-disordered breathing (SDB) in 279 patients with T2DM (apnoea-hypopnoea index $[\mathrm{AHI}] \geq 10$ ). ${ }^{(4)}$ Zhang et al found that $60 \%$ of 880 hospitalised patients with T2DM had SDB, based on a two-channel portable sleep monitoring device. ${ }^{(5)}$ Questionnaire-based screening of T2DM patients found that up to $50 \%$ of them were at risk for OSA. ${ }^{(6)}$

A retrospective, population-based study of 16,066 patients with $\mathrm{T} 2 \mathrm{DM}$ in the primary care setting revealed that $18 \%$ of the study population had OSA, diagnosed based on polysomnography. Among obese patients, the prevalence of OSA was said to be $23 \%{ }^{(7)}$ Although these rates are lower than in nonpolysomnography-based studies, they are still significantly higher than those in the general population, highlighting the possible effect of T2DM on OSA. In one of the largest cohort studies with more than ten years of follow-up, the incident rate of T2DM was
$30 \%$ higher in subjects with severe OSA ( $\mathrm{AHI}>30)$ than in those with $\mathrm{AHI}<5$. $^{(8)}$

Studies in Asian OSA populations reported a similar prevalence of T2DM to those in Europe and the United States. The prevalence of diabetes mellitus (DM) in a Japanese OSA cohort ${ }^{(9)}$ was reported to be $25.9 \%$, four times higher than that of the control group, and the prevalence in a Chinese cohort was $16.3 \% .{ }^{(10)}$ Further studies in Chinese examining insulin sensitivity (homeostatic model assessment of insulin resistance, or HOMA-IR) and pancreatic betacell function (homeostatic model assessment of beta-cell function, or HOMA-beta) found that fasting insulin level and HOMA-IR increase by about $0.5 \%$ with every unit increase in $\mathrm{AHI}{ }^{(11,12)}$ In South Korea, habitual snoring was found to be associated with higher odds of elevated glycated haemoglobin levels (HbA1c) in a non-obese and normoglycaemic population sample. ${ }^{(13)}$

\section{ASSOCIATIONS BETWEEN OSA AND T2DM}

Establishing causality and reciprocity in these illnesses is difficult, as major studies examining the link between these two illnesses have varying research methodologies and outcome measures. While polysomnography is the gold standard for diagnosing OSA, there are multiple criteria for diagnosing T2DM and pre-DM. These include fasting plasma glucose level $\geq 7.0$ $\mathrm{mmol} / \mathrm{L}$, two-hour plasma glucose level $\geq 11.1 \mathrm{mmol} / \mathrm{L}$ on an oral glucose tolerance test, $\mathrm{HbA} 1 \mathrm{c} \geq 6.5 \%$, or random plasma glucose level $\geq 11.1 \mathrm{mmol} / \mathrm{L}$ in symptomatic patients. ${ }^{(14)}$ To add to the confusion, prediabetic states of impaired fasting glucose and impaired glucose tolerance should also be considered. ${ }^{(14)}$ Other than these conventional measures of glucose metabolism, some studies utilised the hyperinsulinaemic-euglycaemic clamp (the gold standard for assessing insulin sensitivity); HOMA-IR for measuring insulin resistance and HOMA-beta for insulin secretion; the frequently sampled intravenous glucose tolerance

${ }^{1}$ Department of Respiratory and Critical Care Medicine, Tan Tock Seng Hospital, Singapore, ${ }^{2}$ Stanford Sleep Medicine Center, Department of Psychiatry and Behavioral Sciences, Stanford University School of Medicine, California, United States

Correspondence: Dr Chuen Peng Lee, Consultant, Department of Respiratory and Critical Care Medicine, Tan Tock Seng Hospital, 11 Jalan Tan Tock Seng, Singapore 308433. chuen_peng_lee@ttsh.com.sg 
test; and the short insulin tolerance test for insulin sensitivity. ${ }^{(15)}$ The plethora of outcome measures has challenged the grounds for making consistent comparisons across studies. Nevertheless, multiple studies have suggested a relationship between OSA and DM, which is most likely bidirectional.

In the Sleep Heart Health Study, SDB was independently associated with fasting glucose intolerance. Subjects with abnormal respiratory disturbance index ( $\geq 5 /$ hour) had an increased risk of glucose intolerance and insulin resistance, as measured by the HOMA index and the oral glucose tolerance test. ${ }^{(16)}$ Reichmuth et al sought to examine the prevalence and incidence of T2DM in subjects with SDB in the Wisconsin Sleep Cohort. A diagnosis of T2DM was established through physicians' reports or fasting plasma glucose levels. They reported that $14.7 \%$ of subjects with $\mathrm{AHI} \geq 15$ were diagnosed to be diabetic, compared with $2.8 \%$ of subjects with $\mathrm{AHI}<5$. When compared to subjects with $\mathrm{AHI}<5$, those with $\mathrm{AHI} \geq 15$ were 1.6 times more likely to develop T2DM within four years of initial testing. ${ }^{(17)}$ A cross-sectional analysis of 6,616 participants in the European Sleep Apnea Cohort study confirmed the increased prevalence of T2DM among patients with OSA: the prevalence of T2DM was $6.6 \%$ in subjects without OSA, in contrast to $28.9 \%$ in those with severe OSA. Through measurements of $\mathrm{HbA1c}$, the study also showed that glycaemic control worsened with more severe OSA. ${ }^{(18)}$

\section{PATHOPHYSIOLOGY}

The pathophysiology of OSA is characterised by recurrent upper airway collapse that triggers hypopnoea and apnoea, resulting in impaired blood gas exchanges, fragmented sleep and systemic inflammation. ${ }^{(19,20)}$ Intermittent hypoxaemia (IH) and sleep fragmentation (SF) are two important corroborators in the pathogenesis of T2DM. Sympathetic system activation, hypothalamic-pituitary-adrenal (HPA) axis alterations, adipokines disturbances, systemic inflammation and oxidative stress are intermediary pathways leading to the development of T2DM.

$\mathrm{IH}$ plays a pivotal role in the pathogenesis of T2DM in OSA subjects. In rodent models, acute exposure to $\mathrm{IH}$ led to a decrease in whole-body insulin sensitivity, as determined by the hyperinsulinaemic-euglycaemic clamp and decreased glucose utilisation resulting from reduced insulin sensitivity in the oxidative, insulin-sensitive soleus muscle. ${ }^{(21)}$ Increased oxidative stress from tissue lipid peroxidation and increased cortisone levels were also demonstrated using $\mathrm{IH}$ in mice. ${ }^{(22,23)}$ Changes in glucose metabolism following withdrawal of one week of $\mathrm{IH}$ appeared irreversible $\mathrm{e}^{(23)}$ and may be a reason for the absence of an overwhelming treatment effect of continuous positive airway pressure (CPAP). ${ }^{(24)}$ When the frequently sampled intravenous glucose tolerance test was utilised to assess glucose metabolism in healthy volunteers, it was found that IH impaired insulin sensitivity, glucose effectiveness and insulin secretion independent of HPA activation. ${ }^{(25)}$ In the Japanese Circulatory Risk in Communities Study, nocturnal IH (as measured by $3 \%$ oxygen desaturation index) was shown to be independently associated with the risk of T2DM. ${ }^{(26)}$ In addition, this effect of $\mathrm{IH}$ was not exacerbated by daytime sleepiness or sleep duration in the French SYNAPSE cohort. ${ }^{(27)}$
Recurrent nocturnal hypoxaemia and frequent arousals from SF may cause the HPA axis to lose the ability to respond to chronic recurring stress. Nocturnal hypercortisolism accompanied by low morning cortisol level was found in severe OSA subjects, who had higher insulin resistance when compared to controls. ${ }^{(28)}$

Systemic inflammation, surrogated by high-sensitivity C-reactive protein, fibrinogen, uric acid, and oxidative stress by the expression of inflammatory cytokines, were found to be high in studies of subjects with OSA. ${ }^{(29,30)}$ Vgontzas et al postulated that the proliferation of tumour necrosis factor-alpha in the pro-inflammatory state of OSA suppresses the synthesis of the antidiabetic hormone, adiponectin, resulting in a predisposition to develop T2DM. ${ }^{(31)}$ Adipocytes play a significant role in the regulation of glucose metabolism through the adipokines: resistin, adiponectin and leptin. ${ }^{(32)} \mathrm{H}$, through hypoxic adipocytes, results in the dysregulation of the expressions of these adipokines, leading to insulin resistance and impaired glucose tolerance. ${ }^{(33)}$ Resistin levels have been shown to correlate with insulin resistance in both lean and obese subjects. ${ }^{(34)}$ Pro-inflammatory resistin and interleukin-6 (IL-6) were found to be higher in untreated OSA subjects. In addition, resistin was found to have an independent linear relationship with average blood oxygen saturation and IL-6 levels. ${ }^{(35)}$ CPAP was found to be effective in decreasing the levels of resistin and IL-6.

SF is a consequence of recurrent arousals from sleep in OSA. Instrumental SF was seen to aggravate glucose intolerance in mice. ${ }^{(36)}$ Although the relationship between SF and glucose intolerance may be secondary to sustained hypothalamopituitary axis activation and cortisol secretion, SF may play a synergistic role. Additionally, SF is analogous to involuntary sleep deprivation, and sleep deprivation has been associated with insulin resistance and T2DM. In a Taiwanese population cohort, short sleepers $(<6.0$ hours) had a higher risk of newly diagnosed DM even after adjusting for potential confounding factors, including lifestyle, obesity and family history. ${ }^{(37)}$ Data on self-reported sleep duration in the First National Health and Nutrition Examination Survey revealed that sleep duration $\leq 5$ hours was associated with higher odds ratio of incident DM. ${ }^{(38)}$ Rapid eye movement (REM) sleep deprivation was demonstrated, in rodents, to affect glucose metabolism through effects on hexokinase and glucose 6-phosphatase. ${ }^{(39)} \mathrm{REM} \mathrm{AHI}$, in contrast to non-REM AHI, was also independently associated with increasing $\mathrm{HbA} 1 \mathrm{c}$ in OSA patients. Extending CPAP usage time from four to seven hours was estimated to cover more than $85 \%$ of REM sleep and reduced $\mathrm{HbA} 1 \mathrm{c}$ by up to $1 \%{ }^{(40)}$ On the contrary, a study in nine human subjects showed that slow-wave sleep suppression and not REM deprivation led to reduced insulin sensitivity and glucose tolerance. ${ }^{(41)}$

Much of the aforementioned evidence indicates that OSA is culpable for the outcome of T2DM. Little evidence exists to support the converse, ${ }^{(7,42)}$ especially if the potent confounder of obesity is removed. ${ }^{(3,43,44)}$ However, it has also been postulated that autonomic neuropathy in T2DM results in dysfunction of the mechanoreceptor reflex controlling the upper airway dilator, hence predisposing the patient to develop OSA. ${ }^{(45)}$ This was 
demonstrated in non-obese subjects.

There is contradictory data on the beneficial effects of CPAP on glucose metabolism, which is possibly accounted for by suboptimal compliance and insufficient treatment duration. A systematic review of randomised controlled trials of CPAP compared with sham CPAP failed to demonstrate significant beneficial treatment effects on glucose metabolism. ${ }^{(46)}$ However, recent data showed that CPAP in highly compliant obese individuals without DM improved glucose metabolism and may ameliorate their risk for the development of overt DM. ${ }^{(47,48)}$

\section{CONCLUSION}

There is strong evidence that OSA, through $\mathrm{IH}$ and $\mathrm{SF}$, is associated with a predisposition to develop T2DM. However, the benefits of CPAP for OSA treatment to prevent T2DM or improve disease control remain doubtful.

\section{REFERENCES}

1. Punjabi NM. The epidemiology of adult obstructive sleep apnea. Proc Am Thorac Soc 2008; 5:136-43.

2. Shaw JE, Sicree RA, Zimmet PZ. Global estimates of the prevalence of diabetes for 2010 and 2030. Diabetes Res Clin Pract 2010; 87:4-14.

3. Foster GD, Sanders MH, Millman R, et al; Sleep AHEAD Research Group. Obstructive sleep apnea among obese patients with type 2 diabetes. Diabetes Care 2009; 32:1017-9.

4. Einhorn D, Stewart DA, Erman MK, et al. Prevalence of sleep apnea in a population of adults with type 2 diabetes mellitus. Endocr Pract 2007; 13:355-62.

5. Zhang R, Zhang P, Zhao F, Han X, Ji L. Association of diabetic microvascular complications and parameters of obstructive sleep apnea in patients with type 2 diabetes. Diabetes Technol Ther 2016; 18:415-20.

6. Keskin A, Ünalacak M, Bilge $U$, et al. Effects of sleep disorders on hemoglobin A1c levels in type 2 diabetic patients. Chin Med J (Engl) 2015; 128:3292-7.

7. Heffner JE, Rozenfeld Y, Kai M, Stephens EA, Brown LK. Prevalence of diagnosed sleep apnea among patients with type 2 diabetes in primary care. Chest 2012; 141:1414-21.

8. Kendzerska T, Gershon AS, Hawker G, Tomlinson G, Leung RS. Obstructive sleep apnea and incident diabetes. A historical cohort study. Am J Respir Crit Care Med 2014; 190:218-25.

9. Otake K, Sasanabe R, Hasegawa R, et al. Glucose intolerance in Japanese patients with obstructive sleep apnea. Intern Med 2009; 48:1863-8.

10. Hui $P$, Zhao L, Xie Y, et al. Nocturnal hypoxemia causes hyperglycemia in patients with obstructive sleep apnea and type 2 diabetes mellitus. Am J Med Sci 2016; 351:160-8.

11. Ip MS, Lam B, Ng MM, et al. Obstructive sleep apnea is independently associated with insulin resistance. Am J Respir Crit Care Med 2002; 165:670-6.

12. Gu CJ, Li M, Li QY, et al. Obstructive sleep apnea is associated with impaired glucose metabolism in Han Chinese subjects. Chin Med J (Engl) 2013; 126:5-10.

13. Joo S, Lee S, Choi HA, et al. Habitual snoring is associated with elevated hemoglobin A1c levels in non-obese middle-aged adults. J Sleep Res 2006; 15:437-44.

14. American Diabetes Association. Diagnosis and classification of diabetes mellitus. Diabetes Care 2009; 32 Suppl 1:S62-7.

15. Lam DC, Lam KS, Ip MS. Obstructive sleep apnoea, insulin resistance and adipocytokines. Clin Endocrinol (Oxf) 2015; 82:165-77.

16. Punjabi NM, Shahar E, Redline S, et al; Sleep Heart Health Study Investigators. Sleep-disordered breathing, glucose intolerance, and insulin resistance: the Sleep Heart Health Study. Am J Epidemiol 2004; 160:521-30.

17. Reichmuth KJ, Austin D, Skatrud JB, Young T. Association of sleep apnea and type II diabetes: a population-based study. Am J Respir Crit Care Med 2005; 172:1590-5.

18. Kent BD, Grote L, Ryan S, et al. Diabetes mellitus prevalence and control in sleep-disordered breathing: the European Sleep Apnea Cohort (ESADA) study. Chest 2014; 146:982-90.

19. Nácher M, Serrano-Mollar A, Farré R, et al. Recurrent obstructive apneas trigger early systemic inflammation in a rat model of sleep apnea. Respir Physiol Neurobiol 2007; 155:93-6.

20. Eckert DJ, Malhotra A. Pathophysiology of adult obstructive sleep apnea. Proc Am Thorac Soc 2008; 5:144-53.

21. liyori N, Alonso LC, Li J, et al. Intermittent hypoxia causes insulin resistance in lean mice independent of autonomic activity. Am J Respir Crit Care Med 2007; 175:851-7.

22. Yokoe T, Alonso LC, Romano LC, et al. Intermittent hypoxia reverses the diurnal glucose rhythm and causes pancreatic beta-cell replication in mice. J Physiol 2008; 586:899-911.

23. Polak J, Shimoda LA, Drager LF, et al. Intermittent hypoxia impairs glucose homeostasis in C57BL6/J mice: partial improvement with cessation of the exposure. Sleep 2013; 36:1483-90; 1490a-b.

24. Martínez-Ceron E, Fernández-Navarro I, Garcia-Rio F. Effects of continuous positive airway pressure treatment on glucose metabolism in patients with obstructive sleep apnea. Sleep Med Rev 2016; 25:121-30.

25. Louis M, Punjabi NM. Effects of acute intermittent hypoxia on glucose metabolism in awake healthy volunteers. J Appl Physiol (1985) 2009; 106:1538-44.

26. Muraki I, Tanigawa T, Yamagishi K, et al; CIRCS Investigators. Nocturnal intermittent hypoxia and the development of type 2 diabetes: the Circulatory Risk in Communities Study (CIRCS). Diabetologia 2010; 53:481-8.

27. Assoumou HG, Gaspoz JM, Sforza E, et al. Obstructive sleep apnea and the metabolic syndrome in an elderly healthy population: the SYNAPSE cohort. Sleep Breath 2012; 16:895-902.

28. Bozic J, Galic T, Supe-Domic D, et al. Morning cortisol levels and glucose metabolism parameters in moderate and severe obstructive sleep apnea patients. Endocrine 2016; 53:730-9.

29. Hermans MP, Ahn SA, Mahadeb YP, Rousseau MF. Sleep apnoea syndrome and 10-year cardiovascular risk in females with type 2 diabetes: relationship with insulin secretion and insulin resistance. Diabetes Metab Res Rev 2013; 29:227-34

30. Vatansever E, Surmen-Gur E, Ursavas A, Karadag M. Obstructive sleep apnea causes oxidative damage to plasma lipids and proteins and decreases adiponectin levels. Sleep Breath 2011; 15:275-82.

31. Vgontzas AN, Papanicolaou DA, Bixler EO, et al. Elevation of plasma cytokines in disorders of excessive daytime sleepiness: role of sleep disturbance and obesity. J Clin Endocrinol Metab 1997; 82:1313-6.

32. Ailhaud G. Adipose tissue as a secretory organ: from adipogenesis to the metabolic syndrome. C R Biol 2006; 329:570-7; discussion 653-5.

33. Fu C, Jiang L, Zhu F, et al. Chronic intermittent hypoxia leads to insulin resistance and impaired glucose tolerance through dysregulation of adipokines in nonobese rats. Sleep Breath 2015;19:1467-73.

34. Silha JV, Krsek M, Skrha JV, et al. Plasma resistin, adiponectin and leptin levels in lean and obese subjects: correlations with insulin resistance. Eur J Endocrinol 2003; 149:331-5.

35. Yamamoto Y, Fujiuchi S, Hiramatsu M, et al. Resistin is closely related to systemic inflammation in obstructive sleep apnea. Respiration 2008; 76:377-85.

36. Baud MO, Magistretti PJ, Petit JM. Sustained sleep fragmentation affects brain temperature, food intake and glucose tolerance in mice. J Sleep Res 2013; 22:3-12.

37. Chao CY, Wu JS, Yang YC, et al. Sleep duration is a potential risk factor for newly diagnosed type 2 diabetes mellitus. Metabolism 2011; 60:799-804.

38. Gangwisch JE, Heymsfield SB, Boden-Albala B, et al. Sleep duration as a risk factor for diabetes incidence in a large US sample. Sleep 2007; 30:1667-73.

39. Thakkar M, Mallick BN. Rapid eye movement sleep-deprivation-induced changes in glucose metabolic enzymes in rat brain. Sleep 1993; 16:691-4.

40. Grimaldi D, Beccuti G, Touma C, Van Cauter E, Mokhlesi B. Association of obstructive sleep apnea in rapid eye movement sleep with reduced glycemic control in type 2 diabetes: therapeutic implications. Diabetes Care 2014; 37:355-63.

41. Herzog N, Jauch-Chara K, Hyzy F, et al. Selective slow wave sleep but not rapid eye movement sleep suppression impairs morning glucose tolerance in healthy men. Psychoneuroendocrinology 2013; 38:2075-82.

42. Schober AK, Neurath MF, Harsch IA. Prevalence of sleep apnoea in diabetic patients. Clin Respir J 2011; 5:165-72.

43. Katsumata K, Okada T, Miyao M, Katsumata Y. High incidence of sleep apnea syndrome in a male diabetic population. Diabetes Res Clin Pract 1991; 13:45-51.

44. Cizza G, Piaggi P, Lucassen EA, et al. Obstructive sleep apnea is a predictor of abnormal glucose metabolism in chronically sleep deprived obese adults. PLoS One 2013; 8:e65400.

45. Bottini P, Dottorini ML, Cristina Cordoni M, Casucci G, Tantucci C. Sleepdisordered breathing in nonobese diabetic subjects with autonomic neuropathy. Eur Respir J 2003; 22:654-60.

46. Jullian-Desayes I, Joyeux-Faure M, Tamisier R, et al. Impact of obstructive sleep apnea treatment by continuous positive airway pressure on cardiometabolic biomarkers: a systematic review from sham CPAP randomized controlled trials. Sleep Med Rev 2015; 21:23-38.

47. Pamidi S, Wroblewski K, Stepien M, et al. Eight hours of nightly continuous positive airway pressure treatment of obstructive sleep apnea improves glucose metabolism in patients with prediabetes. A randomized controlled trial. Am J Respir Crit Care Med 2015; 192:96-105.

48. Salord N, Fortuna AM, Monasterio C, et al. A randomized controlled trial of continuous positive airway pressure on glucose tolerance in obese patients with obstructive sleep apnea. Sleep 2016; 39:35-41. 